\section{Dement Geriatr Cogn Disord Extra 2012;2:481-495}

DOI: $10.1159 / 000343480$

(c) 2012 S. Karger AG, Basel

Published online: November 9, 2012

www.karger.com/dee

\title{
White Matter Hyperintensities in Mild Lewy Body Dementia
}

\author{
K. Oppedal ${ }^{\mathrm{a}, \mathrm{c}} \quad$ D. Aarsland ${ }^{\mathrm{a}}{ }^{\mathrm{f}}$ M.J. Firbank ${ }^{\mathrm{g}} \quad$ H. Sonnesyn ${ }^{\mathrm{a}}$ \\ O.B. Tysnes ${ }^{d}$ J.T. O'Brieng M.K. Beyer ${ }^{\mathrm{a}}{ }^{\mathrm{b}}$, e
}

${ }^{a}$ Centre for Age-Related Medicine, ${ }^{b}$ The Norwegian Center for Movement Disorders, Stavanger University Hospital, and ' Department of Electrical Engineering and Computer Science, University of Stavanger, Stavanger, ${ }^{\mathrm{d}}$ Department of Neurology, Haukeland University Hospital, Bergen, and 'Department of Radiology and Nuclear Medicine, Oslo University Hospital, Oslo, Norway; ${ }^{f}$ Alzheimer's Disease Research Centre, Karolinska Institutet, Stockholm, Sweden; gInstitute for Ageing and Health, Wolfson Research Centre, Newcastle upon Tyne, UK

\section{Key Words}

Cerebrovascular diseases - Cognition • Alzheimer's dementia - Lewy body dementia • Parkinson's disease $\cdot$ Magnetic resonance imaging $\cdot$ White matter hyperintensities

\begin{abstract}
Background: The objective of this study was to explore the load of white matter hyperintensities (WMH) in patients with Lewy body dementia (LBD) and compare to Alzheimer's disease (AD) and normal controls (NC). Methods: Diagnosis of LBD and AD was made according to consensus criteria and cognitive tests were administered. MRI scans for 77 (61 AD and 16 LBD) patients and 37 healthy elderly control subjects were available for analysis. We segmented WMH from FLAIR images using an automatic thresholding technique and calculated the volume of WMH in several regions of the brain, using non-parametric tests to compare groups. Multivariate regression was applied. Results: There were no significant differences in WMH between AD and LBD. We found a significant correlation between total and frontal WMH and Mini-Mental State Examination (MMSE) and verbal fluency scores in the AD group, but not in the LBD group. Conclusion: The WMH load in LBD was similar to that of AD. A correlation between WMH load and cognition was found in the AD group, but not in the LBD group, suggesting that vascular disease contributes to cognitive impairment in AD but not LBD.

Copyright $\odot 2012$ S. Karger AG, Basel
\end{abstract}




\section{Introduction}

White matter hyperintensities (WMH) are localized areas of increased signal in the brain white matter visible on T2-weighted images. They are typically seen around the ventricles (periventricular WMH), but also as focal lesions in the deep white matter. It is generally considered that in the elderly, WMH represent small vessel cerebrovascular disease (CVD) [1]. WMH are found with increased frequencies with increasing age in healthy subjects [2], but they are also found to be associated with Alzheimer's disease (AD) [3]. Vascular dementia is thought to be the consequence of small vessel CVD which results in increased WMH [4]. Clinical symptoms associated with WMH include gait disturbances [5], depression [6], and cognitive impairment [7].

Dementia with Lewy bodies (DLB) is the second most common neurodegenerative dementia and together with dementia associated with Parkinson's disease (PDD), it accounts for $15-20 \%$ of people with dementia [8]. The defining pathological feature is Lewy body degeneration in the brain stem, forebrain, and limbic and cortical structures, and the two syndromes are often combined into a Lewy body dementia (LBD) group $[9,10]$. However, the relationship between localization and density of Lewy bodies with clinical dementia symptoms is not strong [11], suggesting that other pathologies contribute as well, such as AD pathology and vascular brain changes, which are common in the elderly and may contribute to the clinical presentation of LBD. For example, vascular changes in the basal ganglia are common in the elderly and may cause parkinsonism [12].

Understanding the role of $\mathrm{WMH}$ for the pathogenesis of the progression of cognitive impairment is important, since preventing WMH may represent a target for future attempts to prevent or slow down the disease process. It is particularly important to study this in the early phase of the disease, as this will likely be the target for future treatment.

Few studies have explored the severity and consequences of WMH in DLB, and the reported findings are inconsistent. In a study of $48 \mathrm{DLB}$ and $45 \mathrm{AD}$ cases, Londos et al. [13] found that the DLB group had a higher prevalence of frontal white matter pathology, mostly of the ischemic type compared to AD. In contrast, in a small study of autopsy-confirmed LBD ( $\mathrm{n}=13)$, the extent of Lewy body pathology was inversely correlated to the severity of most vascular pathologies [14]. In an imaging study comparing baseline WMH in subjects with AD ( $\mathrm{n}=23)$, PDD $(\mathrm{n}=13)$, and DLB $(\mathrm{n}=14)$, WMH volume (as a percentage of brain volume) was significantly higher for $\mathrm{AD}$ versus controls, but not significantly different between LBD and controls [15]. The above studies have been performed in subjects with endstage disease (autopsy studies) or with moderate to severe dementia. Thus, there is a need to clarify the influence of WMH in mild LBD. The aim of this study was to measure the total and regional volume of WMH in patients with mild AD and LBD using a semi-automatic method, and to explore the association with cognitive impairment including memory and executive function.

\section{Methods}

\section{Subjects}

From March 2005 to March 2007, we screened all referrals to five outpatient clinics in geriatric medicine and old age psychiatry in the counties of Rogaland (Stavanger and Haugesund) and Hordaland (Bergen) in Western Norway. Inclusion criteria were a first-time diagnosis of mild dementia according to ICD-10, and a minimum Mini-Mental State Examination (MMSE) score of 20. From 2007 on, we selectively recruited patients with DLB and PDD. Additionally, three neurology outpatient clinics in the same area were contacted, and agreed 


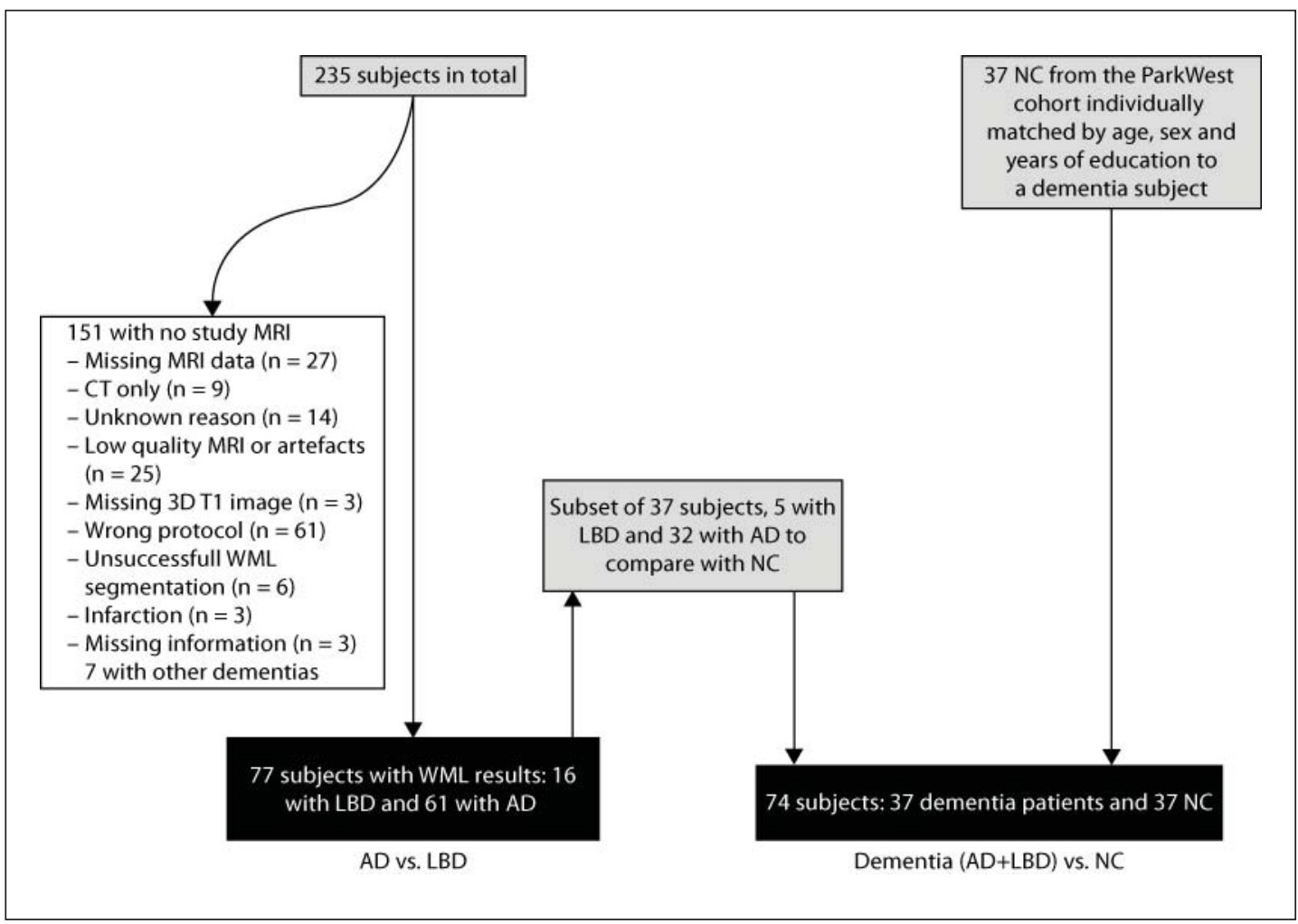

Fig. 1. Flow chart representing the selection of the current MRI study sample from the initial DemWest study cohort. WML $=$ White matter lesion.

to refer new dementia cases to one of the participating centers. The patients and their caregivers were first seen by the study clinician, who performed a structured clinical interview of demographic and clinical data. The comprehensive assessment procedure included a detailed history using a semi-structured interview, clinical examination including physical, neurological, psychiatric, and neuropsychological examinations, and routine blood tests. A total of 235 subjects fulfilled inclusion criteria. Patients are followed annually with the same assessment battery. Patients with acute delirium, terminal illness, recently diagnosed with a major somatic illness, previous bipolar disorder or psychotic disorder were excluded. Further details of the recruitment process are provided elsewhere [8].

A control group consisting of healthy elderly (NC) was drawn from the Norwegian ParkWest study [16]. They were recruited from spouses, friends, and relatives of patients with PD, and other volunteers in Western and Southern Norway. These subjects were younger than the dementia population, and thus we needed to individually match for sex, age, and years of education. This resulted in $37 \mathrm{NC}$ that matched with 37 patients ( 32 with AD, 5 with LBD).

The Regional Committee for Medical Research Ethics, Western Norway, approved the study. All participants signed informed consent to participate in the study after the study procedures had been explained in detail to the patient and a caregiver, usually the spouse or offspring.

A total of 77 mild dementia subjects, 61 with AD and 16 with LBD, had MRI scans of sufficient quality and were included in this study (see fig. 1 and table 1 for an overview of patient inclusion). As seen in table 2, there were no significant differences between the AD and the LBD group in age or years of education, but there were more males in the LBD than 
Table 1. Baseline clinical characteristics of the dementia subjects with and without WMH volume results

\begin{tabular}{llccl}
\hline Variable & $\mathrm{n}($ excl):n(incl) & Excluded & Included & p value \\
\hline Age, years & $157: 77$ & $75.8(7.7)$ & $75.2(7.2)$ & 0.546 \\
Education, years & $145: 77$ & $9.7(3.1)$ & $9.1(2.4)$ & 0.375 \\
Sex, male:female & $158: 77$ & $70: 87$ & $27: 50$ & $0.298^{\mathrm{a}}$ \\
MMSE & $154: 77$ & $23.6(2.8)$ & $24.0(2.3)$ & 0.387 \\
CVLT-II & $158: 75$ & $19.9(8.4)$ & $19.9(7.5)$ & 0.849 \\
Verbal fluency & $161: 76$ & $11.3(4.4)$ & $11.9(4.4)$ & 0.640 \\
HIS & $141: 76$ & $4.0(2.4)$ & $3.0(2.0)$ & 0.001 \\
APOE $\varepsilon$ 4, yes:no & $100: 51$ & $62: 38$ & $31: 20$ & $0.885^{\mathrm{b}}$ \\
CDR-SOB & $139: 74$ & $5.8(2.7)$ & $4.5(2.1)$ & 0.001 \\
CIRS & $135: 73$ & $0.16(0.51)$ & $0.16(0.41)$ & 0.477 \\
\hline
\end{tabular}

Values in parentheses are standard deviations. Mann-Whitney $U$ test was used, except if otherwise indicated. $\mathrm{n}(\mathrm{excl})=$ Number of patients in the excluded group; $\mathrm{n}(\mathrm{incl})=$ number of patients in the included group. APOE $\varepsilon 4$ yes means subject has at least one APOE $\varepsilon 4$ allele.

a Pearson's $\chi^{2}=2.423{ }^{\text {b }}$ Pearson's $\chi^{2}=0.021$

Table 2. Baseline clinical characteristics of the patients and NC in the study

\begin{tabular}{lccccc}
\hline Variable & $\begin{array}{l}\mathrm{NC} \\
(\mathrm{n}=37)\end{array}$ & $\begin{array}{l}\mathrm{AD} \\
(\mathrm{n}=61)\end{array}$ & $\begin{array}{l}\text { LBD } \\
(\mathrm{n}=16)\end{array}$ & $\begin{array}{l}\mathrm{p} \text { value (overall, } \\
\mathrm{n}=114)\end{array}$ & $\begin{array}{l}\mathrm{p} \text { value (AD vs. } \\
\text { LBD, } \mathrm{n}=77)\end{array}$ \\
\hline Age, years & $70.6(6.2)$ & $75.2(7.7)$ & $75.5(5.2)$ & $0.005^{\mathrm{a}}$ & 0.89 \\
Education, years & $10.0(2.3)$ & $9.3(2.5)$ & $8.5(1.9)$ & $0.042^{\mathrm{a}}$ & 0.176 \\
Sex, male:female & $13: 24$ & $14: 47$ & $13: 3$ & $<0.001^{\mathrm{b}}$ & $<0.001^{\mathrm{b}}$ \\
MMSE & $28.8(1.0)$ & $23.9(2.3)$ & $24.3(2.5)$ & $<0.001^{\mathrm{a}}$ & 0.314 \\
CVLT-II $^{1}$ & - & $19.2(7.0)$ & $23.2(9.3)$ & - & 0.198 \\
Verbal fluency $^{2}$ & - & $13.0(6.2)$ & $11.5(4.2)$ & - & 0.409 \\
Apoe4, yes:no & $11: 25$ & $27: 14$ & $4: 6$ & $0.007^{\mathrm{c}}$ & $0.133^{\mathrm{d}}$ \\
HIS & - & $2.9(2.1)$ & $3.6(1.9)$ & - & 0.109 \\
CDR-SOB $_{\text {CIRS }}^{3}$ & - & $4.4(2.0)$ & $4.8(2.6)$ & - & 0.578 \\
\hline
\end{tabular}

Values in parentheses are standard deviations. Mann-Whitney $U$ test was used, except if otherwise indicated. APOE $\varepsilon 4$ yes means subject has at least one APOE $\varepsilon 4$ allele.

${ }^{1}$ The CVLT-II score is available for $61 \mathrm{AD}$ patients and $14 \mathrm{LBD}$ patients. ${ }^{2}$ The verbal fluency score is available for $60 \mathrm{AD}$ patients and $16 \mathrm{LBD}$ patients. ${ }^{3}$ The CIRS score is available for $61 \mathrm{AD}$ patients and 12 LBD patients. ${ }^{\mathrm{a}}$ Kruskal-Wallis H test. ${ }^{\mathrm{b}}$ Pearson's $\chi^{2}=18.9{ }^{\mathrm{c}}$ Pearson's $\chi^{2}=9.9 ;{ }^{\mathrm{d}}$ Pearson's $\chi^{2}=2.5$.

in the AD group. MMSE was lower and the proportion with at least one apolipoprotein $\mathrm{E} \varepsilon 4$ (APOE $\varepsilon 4$ ) allele was higher in the patient groups, as expected, but did not differ between $\mathrm{AD}$ and $\mathrm{LBD}$ groups. We decided to add $\mathrm{APOE} \varepsilon 4$ as a possible confounder, since it is known to be associated with WMH [17]. California Verbal Learning Test II (CVLT-II), verbal fluency, Clinical Dementia Rating Sum of Boxes Score (CDR-SOB) and Hachinski ischemia scale (HIS) score did not differ between the two dementia groups, but Cumulative Illness Rating Scale for vascular symptoms (CIRS) was significantly lower in the AD group compared to the LBD group. 
Dementia Diagnosis and Clinical Assessment

Diagnoses were made after a detailed assessment, including the use of standardized assessment of hallucinations, parkinsonism and cognitive fluctuations as previously described [8]. The procedures included HIS [18, 19], CDR-SOB [20], and APOE $\varepsilon 4$ genotyping. Transversal ${ }^{123}$ I-FP-CIT SPECT (DaTscan) images through the basal ganglia were visually assessed for most cases with suspect DLB, scoring caudate and putamen in normal, abnormal, or strong abnormal, by one blinded nuclear medicine physician expert to aid in the diagnosis.

Based on assessments, two old age psychiatrists independently applied the diagnostic criteria for AD [21] and DLB [8] at baseline and 2 years later. In cases of disagreement, and in patients fulfilling more than one set of operationalized diagnostic criteria, the final ascertainment was made based on consensus. Seven patients had been submitted to autopsy with a pathological diagnosis consistent with the clinical diagnosis in all cases. Since DLB and PDD have similar clinical and brain changes, they were combined into one group, i.e. LBD (12 DLB, 4 PDD) [9, 10]. The APOE $\varepsilon 4$ genotype was analyzed as previously described [22].

A comprehensive clinical assessment battery was applied including standardized cognitive, psychiatric and neurological instruments, as previously described [8]. The neuropsychological battery included tests of verbal memory (CVLT-II) and executive functioning (semantic verbal fluency) in addition to the MMSE. We used the sum of immediately recalled words from the five presentations of the CVLT (list A) and number of animals listed during $1 \mathrm{~min}$ for the analysis with the WMH measures. More details are presented elsewhere [8].

\section{$M R I$}

The patients were scanned at three different sites: Stavanger University Hospital, Haugesund Hospital, and Haraldsplass Deaconess Hospital. A 1.5-T scanner was used in all three center (Philips Intera in Stavanger and Haugesund, and GE Signa Excite in Bergen), using the same scanner in each center during the entire study period and a common study imaging protocol. Imaging parameters can be found in appendix 1 and have also been previously published [23].

The NC were scanned at four different sites. They were scanned on the same scanners as the patients in Stavanger and Haugesund, and on different scanners in Arendal (1.0T Philips Intera) and Bergen (1.5T Siemens Symphony).

After a visual inspection some patient scans were excluded due to either insufficient image quality, not having both FLAIR and T1 images for the patient, or movement artifacts and other artifacts (see appendix 1 for MRI parameters).

Since the DemWest cohort is a multicenter study, a phantom study of three human volunteers was performed. Details of the procedure can be found in appendix 1. Cronbach's alpha between MR scanners at different centers was 0.958. Cronbach's alpha between two time points varied between 0.982 and 0.995 , indicating excellent reliabilities both between centers and between different time points. A similar phantom study was performed for the ParkWest study, also with excellent reliabilities.

\section{Image Processing and Analysis}

Image analysis was performed according to a method developed and previously published by Firbank et al. [24]. Briefly, the non-brain regions were removed from the T1 image, using the segmentation routines in SPM5 (http://www.fil.ion.ucl.ac.uk/spm). After transforming to the image space of the FLAIR image, the segmented T1 image was used as a mask for scull stripping of the FLAIR image. Then, the WMH were segmented automatically on a slice-by-slice basis from the FLAIR images, with the images in native space, using a threshold determined from the histogram of pixel intensities for each image slice. To explore the re- 
gional distribution of $\mathrm{WMH}$ throughout the brain, a region of interest (ROI) template in standard MNI space was used (Montreal Neurological Institute, http://www.bic.mni.mcgill. ca). This ROI template was transformed from MNI space to the image space (FLAIR) of each subject by use of the normalization routines in SPM5, and the volumes of WMH in each ROI were calculated. The ROI map was based on the Brodmann template [further details can be found in 25].

Because of the variability between the different centers participating in this study, we found it difficult to choose a single threshold level that gave us an acceptable segmentation result without manual editing. A threshold level of 1.2 was chosen, since it gave an overestimation of the lesion load in every subject. Manual editing was then done to correct for this, by removing excess pixels using FSLView (http://www.fmrib.ox.ac.uk/fsl/index.html), a medical image-editing program being a part of the FSL software bundle. One of the authors (H.S.) did the manual editing after training by a consultant radiologist (M.K.B.) who is experienced at evaluation of WMH. We performed inter- and intra-rater reliability testing between the two raters to ensure good quality. They both edited the same ten datasets twice. Once in the beginning to ensure good inter-rater reliability, and a second time at the end to ensure that similar reliability still persisted and to evaluate intra-rater reliability. We found that the excellent intra-class correlation coefficient was 0.998 for inter-rater reliability and 0.964 for intra-rater reliability.

From the segmentation results, we calculated the total WMH volume, the periventricular WMH volume, the deep WMH volume, and the frontal WMH volume as a percentage of total brain volume, and these values were used in further analysis. Total brain volume was obtained calculating the sum of gray and white matter.

\section{Statistical Analysis}

Comparison of demographic variables was done with non-parametric Mann-Whitney and Kruskal-Wallis tests because of the non-normal distribution of the data for age, years of education and MMSE score. Neither of the abovementioned features nor data for WMH volumes became more normally distributed after a log transformation. For sex, Pearson's $\chi^{2}$ was used to test independence between groups. We first compared the matched dementia and NC groups, and subsequently the $\mathrm{AD}$ versus the $\mathrm{LBD}$ group. WMH volume measurements were compared between the dementia group versus NC and between the Alzheimer group and LBD with the non-parametric Mann-Whitney test. Correlations between WMH load and cognitive scores were done calculating the Spearman's correlation coefficient with two-tailed significance. We also applied hierarchical multivariate linear regression analysis to study the associations between cognitive scores and WMH volume, adjusting for demographic variables significantly associated with cognition in bivariate analysis. All statistical tests were performed using PASW Statistics 18, release 18.0.1, and p values $<0.05$ were considered statistically significant.

\section{Results}

Total, periventricular, and deep WMH volumes as percentage of total brain volume in the $\mathrm{AD}$ and $\mathrm{LBD}$ groups are shown in table 3 and figure 2. There were no significant differences in $\mathrm{WMH}$ volumes between the $\mathrm{AD}$ and $\mathrm{LBD}$ groups (total $\mathrm{WMH}: \mathrm{p}=0.238$, periventricular WMH: $\mathrm{p}=0.264$, and deep WMH: $\mathrm{p}=0.444$ ), although LBD patients had higher numerical values for all three WMH measures. The dementia group had numerically higher $\mathrm{WMH}$ volumes than $\mathrm{NC}$ for total and periventricular $\mathrm{WMH}$, but the differences did not reach statistical significance as shown in table 3 and figure 3 . Since the dementia groups were 
E XX T R R A

Dementia

and Geriatric

Cognitive Disorders
Dement Geriatr Cogn Disord Extra 2012;2:481-495

DOI: $10.1159 / 000343480$

Published online: November 9, 2012

(c) 2012 S. Karger AG, Basel

www.karger.com/dee

Oppedal et al.: White Matter Hyperintensities in Mild Lewy Body Dementia
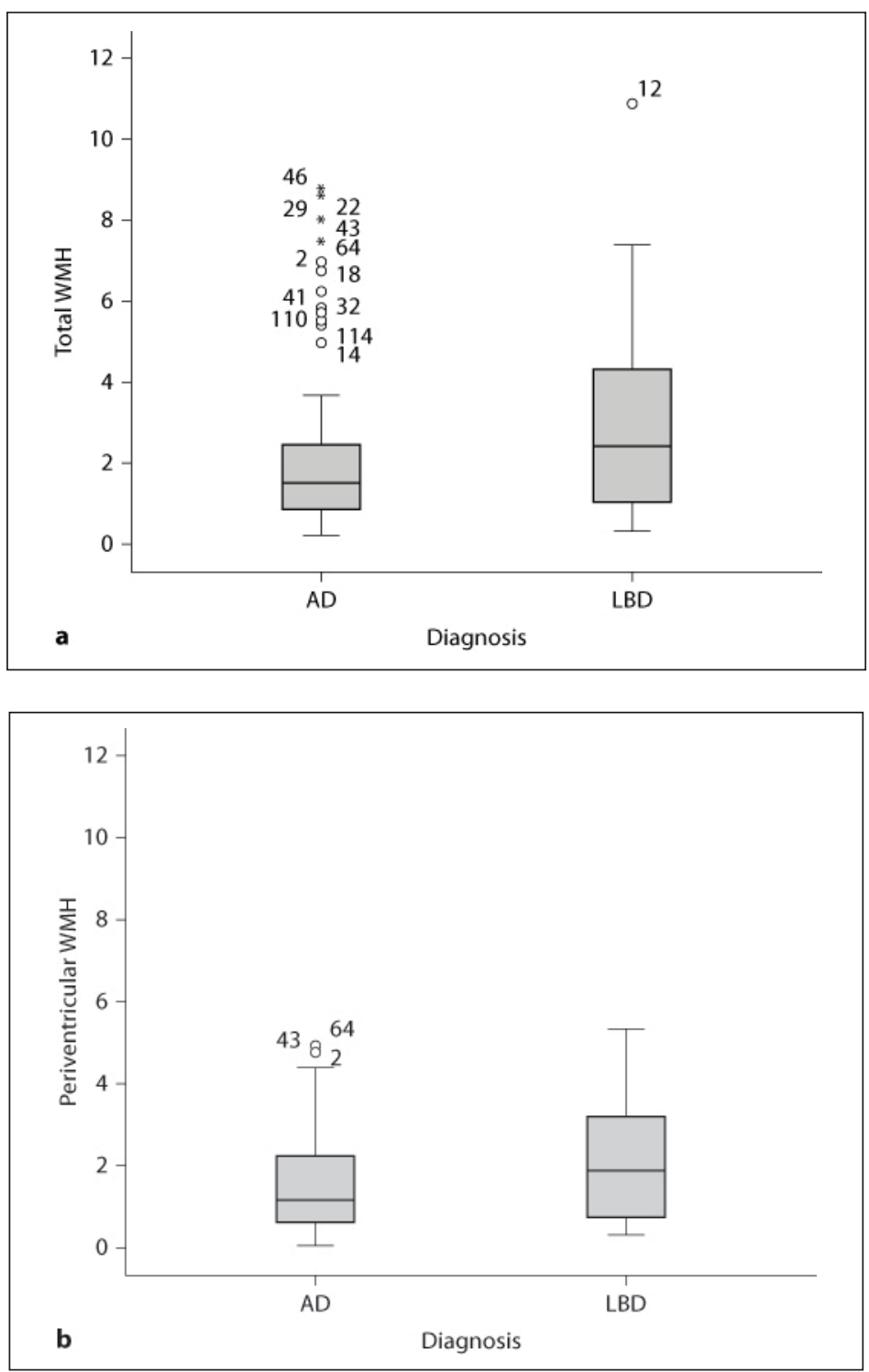

Fig. 2. Box plots showing the distribution of WMH volumes comparing $\mathrm{AD}$ and $\mathrm{LBD}$. a Total WMH in AD vs. LBD. b Periventricular WMH in $\mathrm{AD}$ vs. $\mathrm{LBD}$. c Deep WMH in AD vs. LBD.

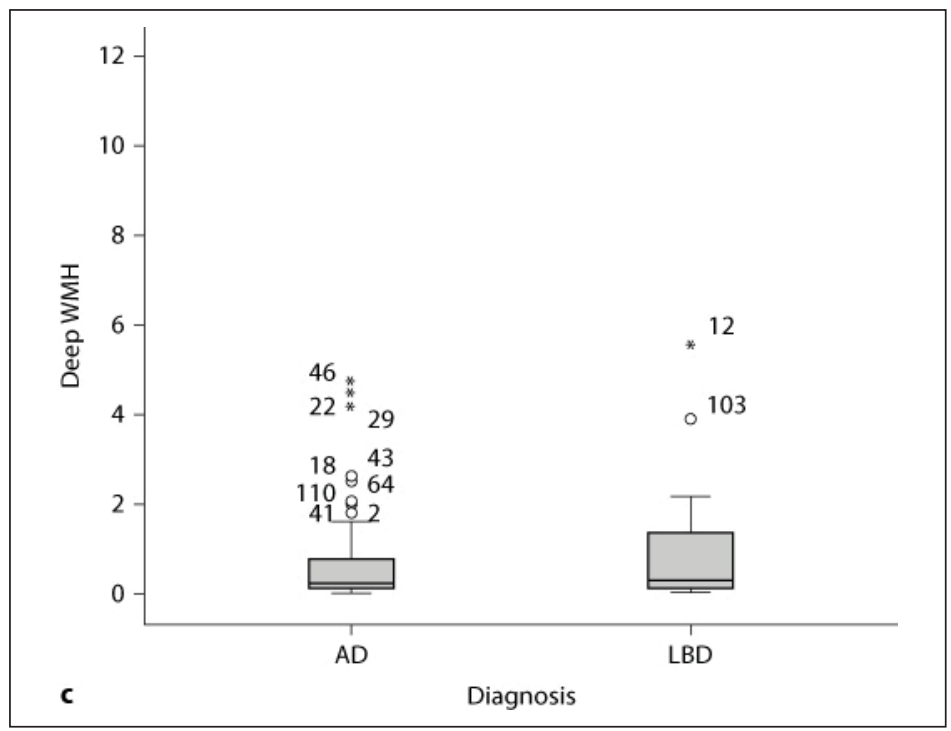


Table 3. WMH volumes between groups

\begin{tabular}{|c|c|c|c|c|c|c|}
\hline Variable & $\begin{array}{l}\mathrm{AD} \\
(\mathrm{n}=61)\end{array}$ & $\begin{array}{l}\text { LBD } \\
(n=16)\end{array}$ & $\begin{array}{l}\mathrm{p} \text { value } \\
\text { (AD vs. } \mathrm{LBD} \text { ) }\end{array}$ & $\begin{array}{l}\text { Subgroup (AD } \\
+\mathrm{LBD}, \mathrm{n}=37 \text { ) }\end{array}$ & $\begin{array}{l}\text { Matched } \\
\text { NC }(n=37)\end{array}$ & $\begin{array}{l}\mathrm{p} \text { value } \\
\text { (demented } \\
\text { vs. } \mathrm{NC} \text { ) }\end{array}$ \\
\hline Median tot_WMH \% & $1.53(1.68)$ & $2.43(3.79)$ & $0.238^{\mathrm{a}}$ & $1.18(1.88)$ & $1.11(0.87)$ & $0.492^{\mathrm{a}}$ \\
\hline Median pvh_WMH \% & $1.16(1.65)$ & $1.89(2.59)$ & $0.264^{\mathrm{a}}$ & $0.88(1.29)$ & $0.61(0.61)$ & $0.185^{\mathrm{a}}$ \\
\hline Median d_WMH \% & $0.24(0.74)$ & $0.31(1.26)$ & $0.444^{\mathrm{a}}$ & $0.18(1.29)$ & $0.35(0.68)$ & $0.499^{\mathrm{a}}$ \\
\hline
\end{tabular}

Values in parentheses are interquartile ranges. AD vs. LBD and a subgroup of demented patients matched for age, sex, and years of education to a group of NC.

tot_WMH \% = Total WMH volume (percentage of total brain volume); pvh_WMH \% = periventricular WMH volume (percentage of total brain volume); d_WMH \% = deep WMH volume (percentage of total brain volume).

a Mann-Whitney U test.

not matched for sex, we examined differences in $\mathrm{WMH}$ in the male subjects (14 AD and 13 LBD) separately - there were no differences between the male AD and LBD patients in either total $(\mathrm{p}=0.141)$, periventricular $(\mathrm{p}=0.325)$, or deep $\mathrm{WMH}(\mathrm{p}=0.202)$.

\section{Association between WMH and Cognition}

In the 77 dementia cases, there were significant correlations between cognitive scores and $\mathrm{WMH}$. We then analyzed $\mathrm{AD}$ and DLB groups separately. In the AD group, total, periventricular, frontal, but not deep WMH correlated (Spearman's rho, $\mathrm{p}$ value) significantly with MMSE and verbal fluency, but not CVLT-II (MMSE; total WMH: -0.361, 0.004, periventricular WMH: $-0.296,0.02$, frontal WMH: $-0.392,0.002$, and fluency; total WMH: $-0.318,0.013$, periventricular WMH: $-0.278,0.031$, frontal WMH: $-0.376,0.003)$. In contrast, the correlations were low and insignificant in the LBD group (table 4). In the AD group, there were correlations between years of education and MMSE, CVLT-II, and fluency. There were significant correlations between age and education and CVLT in the AD group, but not in the DLB group, see table 4 for further details.

Hierarchical multiple regression was used to further study the association between WMH (first total and then frontal WMH volume) and cognition (first MMSE and then verbal fluency). Total WMH explained an additional 5.4\% of the variance in MMSE, after controlling for years of education $\left(\mathrm{R}^{2}\right.$ change $=0.054$, $\mathrm{F}$ change $(1,58)=4.445, \mathrm{p}=0.039$; beta for total WMH was $-0.237, \mathrm{p}=0.039)$. Frontal $\mathrm{WMH}$ explained an additional $4.9 \%$ of the variance in MMSE $\left(\mathrm{R}^{2}\right.$ change $=0.049, \mathrm{~F}$ change $(1,58)=4.030, \mathrm{p}=0.049$; beta for frontal $\mathrm{WMH}$ was $-0.230, \mathrm{p}=0.049)$. There was no significant contribution from $\mathrm{WMH}$ on verbal fluency beyond that of years of education. See table 5 for details.

\section{Discussion}

Using a semi-automatic method to measure volumes of WMH intensities on FLAIR images, similar levels of WMH were found in patients with mild AD and LBD. WMH load was associated with cognition in $\mathrm{AD}$, but not in $\mathrm{LBD}$, suggesting that although $\mathrm{LBD}$ have $\mathrm{WMH}$ similar to $\mathrm{AD}, \mathrm{WMH}$ contributes to cognitive decline in $\mathrm{AD}$, but not $\mathrm{LBD}$.

Earlier studies have shown that WMH volume is increased in AD patients compared to elderly people without dementia [6], but few previous studies of WMH in LBD exist. In a 
EXXIT RAA

Dementia

and Geriatric

Cognitive Disorders
Dement Geriatr Cogn Disord Extra 2012;2:481-495

DOI: 10.1159/000343480

Published online: November 9, 2012

(c) 2012 S. Karger AG, Basel

www.karger.com/dee

Oppedal et al.: White Matter Hyperintensities in Mild Lewy Body Dementia
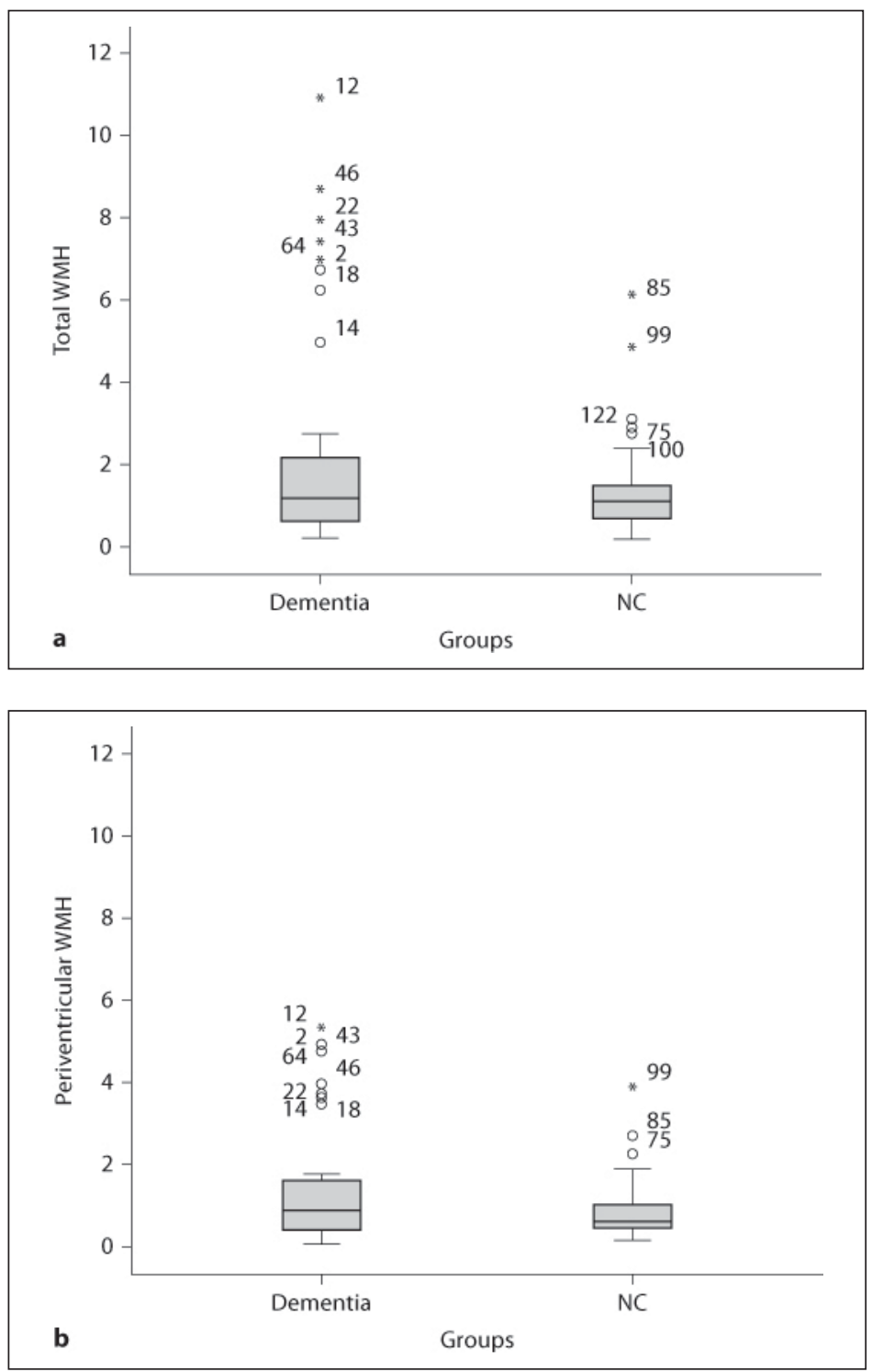

Fig. 3. Box plots showing the distribution of WMH volumes comparing dementia and NC. a Total WMH in dementia vs. NC. b Periventricular WMH in dementia vs. NC. c Deep WMH in dementia vs. NC.

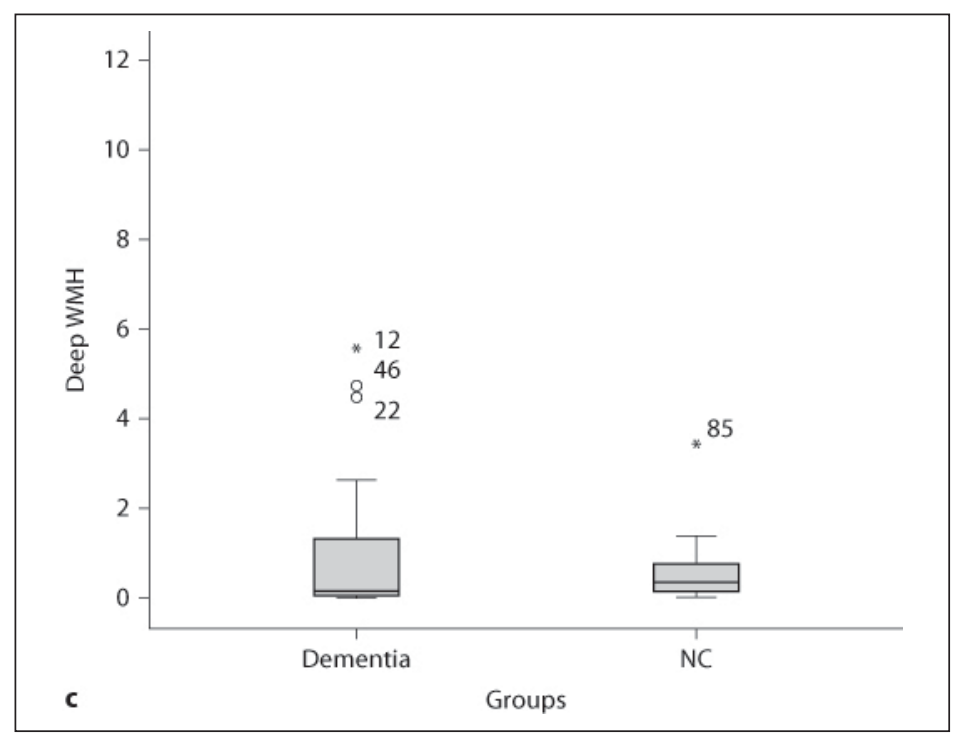


Table 4. Nonparametric bivariate correlations between WMH volume and cognition score in the different groups of the study and different scores for cognition and between age and different scores for cognition

\begin{tabular}{lcc}
\hline Variable & $\mathrm{AD}$ & $\mathrm{LBD}$ \\
\hline MMSE & $\mathrm{n}=61$ & $\mathrm{n}=16$ \\
tot_WMH & $-0.361(0.004)$ & $0.008(0.978)$ \\
pvh_WMH & $-0.296(0.02)$ & $-0.048(0.859)$ \\
d_WMH & $-0.227(0.078)$ & $0.183(0.497)$ \\
Frontal WMH & $-0.392(0.002)$ & $0.023(0.933)$ \\
Age & $-0.150(0.249)$ & $-0.056(0.836)$ \\
Education & $0.461(0.000)$ & $0.195(0.468)$ \\
Sex & $-0.08(0.542)$ & $-0.107(0.692)$ \\
\hline CVLT-II & $\mathrm{n}=61$ & $\mathrm{n}=14$ \\
tot_WMH & $-0.098(0.451)$ & $-0.002(0.994)$ \\
pvh_WMH & $-0.171(0.188)$ & $-0.122(0.679)$ \\
d_WMH & $0.078(0.552)$ & $0.164(0.576)$ \\
Frontal WMH & $-0.148(0.254)$ & $-0.064(0.828)$ \\
Age & $-0.316(0.013)$ & $-0.512(0.061)$ \\
Education & $0.324(0.011)$ & $-0.077(0.794)$ \\
Sex & $0.175(0.177)$ & $-0.239(0.410)$ \\
\hline Verbal fluency & $\mathrm{n}=60$ & $\mathrm{n}=16$ \\
tot_WMH & $-0.318(0.013)$ & $0.101(0.711)$ \\
pvh_WMH & $-0.278(0.031)$ & $0.145(0.592)$ \\
d_WMH & $-0.210(0.107)$ & $0.220(0.412)$ \\
frontal WMH & $-0.376(0.003)$ & $0.086(0.752)$ \\
Age & $-0.195(0.136)$ & $-0.211(0.433)$ \\
Education & $0.422(0.001)$ & $-0.101(0.709)$ \\
Sex & $-0.167(0.203)$ & $0.000(1.000)$ \\
\hline
\end{tabular}

Numbers represent Spearman's rho with $\mathrm{p}$ values in parentheses.

tot_WMH = Total WMH correlation coefficient; pvh_WMH = periventricular WMH correlation coefficient; d_WMH = deep WMH correlation coefficient.

Table 5. Linear hierarchical regression with cognition (MMSE and verbal fluency) as dependent variable, WMH volume as independent variable, and controlling for years of education

\begin{tabular}{lccllrl}
\hline $\begin{array}{l}\text { Independent and dependent } \\
\text { variable } \\
\text { (controlling for education) }\end{array}$ & $\mathrm{R}^{2}$ & $\begin{array}{l}\mathrm{R}^{2} \\
\text { change }\end{array}$ & $\begin{array}{l}\text { F change } \\
(\mathrm{df1}, \mathrm{df2})\end{array}$ & $\begin{array}{l}\text { Sig. F } \\
\text { change }\end{array}$ & $\begin{array}{l}\text { Beta (Educ. } \\
\text { WMH) }\end{array}$ & $\begin{array}{l}\text { Sig. (Educ. } \\
\text { WMH) }\end{array}$ \\
\hline MMSE vs. tot_WMH & 0.299 & 0.054 & $4.445(1,58)$ & 0.039 & $\begin{array}{r}0.447 \\
-0.237\end{array}$ & $\begin{array}{l}0.000 \\
0.039\end{array}$ \\
\hline MMSE vs. frontal WMH & 0.294 & 0.049 & $4.030(1,58)$ & 0.049 & 0.434 & 0.000 \\
& & & & & -0.230 & 0.049 \\
\hline Fluency vs. tot_WMH & 0.153 & 0.003 & $0.182(1,57)$ & 0.671 & 0.377 & 0.004 \\
& & & & & -0.053 & 0.671 \\
\hline Fluency vs. frontal WMH & 0.158 & 0.008 & $0.535(1,57)$ & 0.467 & 0.363 & 0.006 \\
& & & & & -0.092 & 0.467 \\
\hline
\end{tabular}

tot_WMH = Total WMH volume; Sig. = significant; Educ. = education. 
study of patients with AD, PDD, DLB, and NC, the authors did not find any differences between total WMH, periventricular WMH, or total deep WMH in subjects with PDD or LBD compared to controls [15]. Subjects with AD had significantly greater volumes on all three measures compared to controls. This is in line with our results, although in our study, the difference in WMH between dementia and NC groups did not reach significance, possibly related to the small sample size. Another possible explanation is the mild disease stage, since in a 1-year longitudinal follow-up, a significant increase in total WMH within all the individual groups with the exception of the LBD group was found [15]. In a diffusion tensor imaging study where fractional anisotropy values were significantly reduced in a number of white matter areas in the LBD group, no correlations between fractional anisotropy values and MMSE scores were found in the LBD subjects [26]. This could imply a different impact of $\mathrm{WMH}$ in $\mathrm{AD}$ than in $\mathrm{LBD}$, which is consistent with our results.

There are methodological limitations that may have influenced our findings. Due to the insufficient quality of the scans, only a subset of available scans could be included, and thus the sample sizes were relatively small, in particular the LBD group. In addition, the LBD group was a heterogeneous group. Thus, statistical power to detect minor differences may be reduced. In addition, the patients who were included had lower HIS and lower CDR-SOB scores, suggesting that they were slightly healthier than those excluded. Furthermore, this was a cross-sectional study, and thus we cannot conclude whether WMH can cause cognitive decline.

The diagnosis was clinical, and misdiagnosis of AD and LBD cannot be excluded. However, standardized and validated clinical instruments were used, and patients were followed longitudinally. Among 20 patients with a clinical DLB diagnosis, 17 had abnormal uptake in the striatum on DaTscan. A small group with autopsy diagnosis from this cohort $(n=7)$, showed full consistency between pathological and clinical diagnosis. Thus, we believe that the dementia diagnoses are accurate.

Several methods for quantification of WHM severity from MR images of the brain exist [27-29]. A significant limitation of all of the above referenced methods is that they are prone to inter-rater variability. It has been shown that quantification of the actual volume of WMH is a more sensitive approach than the visual rating scales [30]. Others have found that visual rating is as good as the more complex methods in routine clinical practice, but that volumetric assessment should be used in research settings if possible [31].

Automated quantitative segmentation methods are suitable for assessing the impact of WMH on cognitive function [32]. Thus, we decided to use an automatic segmentation method for the volume calculations [33], which is a strength of this study. Since the segmentation method was not robust enough to handle the variation in MR image quality in the DemWest multicenter study, we needed to manually edit the segmentation results to ensure correct results. The reliability of this manual editing between two raters was ascertained. A more robust and fully automatic segmentation method might have increased the accuracy of our results further.

A possible limitation to our study was that we chose to calculate total brain size as the sum of gray matter and white matter, and use it as a point of reference when calculating lesion volume ratios. As age increases and possible dementia evolves, a significant atrophy is expected in both gray and white matter [34, 35]. Others [36] have used total intracranial volume as a reference point, since lower degree of change is normally found here.

In multicenter studies, differences between scanners and differences between imaging protocols are known to impact the results of automatic segmentation methods [37-39]. In our study, we found it difficult to choose a common threshold level to automatically segment the WMH without manual editing, probably caused by slight differences in imaging protocols. This was solved by choosing a method where manual editing was applied, to ensure that 
the reported volumes represent only WMH and not other tissue with similar signal intensity such as fat.

To conclude, we found that although severity of WMH did not differ significantly in mildly demented patients with $\mathrm{AD}$ and $\mathrm{LBD}, \mathrm{WMH}$ were associated with cognitive decline in $\mathrm{AD}$, but not LBD. More studies of the potential clinical impact of WMH in patients with $\mathrm{LBD}$ are needed.

\section{Acknowledgements}

The DemWest study received financial support from the Norwegian Research Council and the Western Norway Regional Health Authority. Ketil Oppedal is supported by grant No. 488107 from the Western Norway Regional Health Authority and from the MedViz - Medical Visualization Network at the University of Bergen. The ParkWest study is supported by the Research Council of Norway (grant No. 177966), the Western Norway Regional Health Authority (grant No. 911218), and by the Norwegian Parkinson's disease Association. This project was also supported by Research grants from the Stavanger University Hospital. Mona K. Beyer is supported by a grant from the Western Norway Regional Health Authority (grant No. 911464). Michael Firbank was supported by the UK NIHR Biomedical Research Centre for Ageing and Age-Related Disease award to the Newcastle upon Tyne Hospitals NHS Foundation Trust. Alexander Lebedev is acknowledged for his contributions to the human phantom study. Prof. Kolbjørn Brønnick is acknowledged for his contribution to the matching of subjects with dementia from the DemWest study with the NC from the ParkWest study.

\section{Disclosure Statement}

Dag Aarsland received honoraria from: Novartis, Lundbeck, GSK, Merck Serono, DiaGenic, GE Health, Orion Pharmaceuticals and research support from Merck Serono, Lundbeck, Novartis.

\section{Appendix}

\begin{tabular}{|c|c|}
\hline $\begin{array}{l}\text { MR imaging } \\
\text { parameters }\end{array}$ & $\begin{array}{l}\text { TR = Repetition time; TE = echo time; TI = inversion time; FA = flip angle; ST = slice } \\
\text { thickness; NEX = number of excitations; FOV = field of view, and VS = voxel size. }\end{array}$ \\
\hline $\begin{array}{l}3 D \text { T1-weight } \\
\text { Stavanger } \\
\text { University } \\
\text { Hospital }\end{array}$ & $\begin{array}{l}\text { sequence } \\
\mathrm{FFE}, \mathrm{TR} / \mathrm{TE} / \mathrm{FA}=10.0 \mathrm{~ms} / 4.6 \mathrm{~ms} / 30^{\circ}, \mathrm{ST}=2 \mathrm{~mm} \text { with } 1 \mathrm{~mm} \text { spacing between slices, } \\
\mathrm{NEX}=2 \text {, Image Matrix }=256 \times 256, \mathrm{FOV} 26 \mathrm{~cm}, \mathrm{VS}=1.0156 \times 1.0156 \times 1 \mathrm{~mm} \text {. }\end{array}$ \\
\hline $\begin{array}{l}\text { Haugesund } \\
\text { Hospital } \\
\text { Haraldsplass } \\
\text { Deaconess } \\
\text { Hospital, } \\
\text { Bergen }\end{array}$ & $\begin{array}{l}\text { FFE, TR/TE/FA } 20.0 \mathrm{~ms} / 4.6 \mathrm{~ms}, 30^{\circ}, \mathrm{ST}=1 \mathrm{~mm} \text { with } 1 \mathrm{~mm} \text { spacing, NEX }=1, \\
\text { Image Matrix }=256 \times 256, \mathrm{FOV} 26 \mathrm{~cm} \text {, VS }=0.5078 \times 0.5078 \times 1 \mathrm{~mm} . \\
\text { FSPGR IR prepped, TR/TE/TI/FA } 8.3 \mathrm{~ms} / 3.2 \mathrm{~ms} / 500 \mathrm{~ms} / 7^{\circ}, \mathrm{ST}=1 \mathrm{~mm} \text { with } 1 \mathrm{~mm} \\
\text { spacing, NEX = } 1 \text {, Image Matrix }=256 \times 256, \text { FOV } 25.6 \mathrm{~cm}, \mathrm{VS}=1 \times 1 \times 1 \mathrm{~mm} .\end{array}$ \\
\hline $\begin{array}{l}\text { Bergen } \\
\text { (ParkWest) }\end{array}$ & $\begin{array}{l}\text { TR/TE/TI/FA 2,130.0/3.9 msec/1,100 msec/15, ST = } 1 \mathrm{~mm} \text { with } 1 \mathrm{~mm} \text { spacing, } \\
\text { NEX 1, Image Matrix } 256 \times 256 \text {, FOV } 25 \mathrm{~cm}, \mathrm{VS}=0.9766 \times 0.9766 \times 1 \mathrm{~mm} \text {. }\end{array}$ \\
\hline Arendal & $\begin{array}{l}\text { FFE, TR/TE/FA } 25 / 6.9 \mathrm{msec} / 30^{\circ}, \mathrm{ST}=2 \mathrm{~mm} \text { with } 2 \mathrm{~mm} \text { spacing, NEX } 1 \text {, Image } \\
\text { Matrix } 256 \times 256 \text {, FOV } 26.0 \mathrm{~cm}, \mathrm{VS}=1.0156 \times 1.0156 \times 2 .\end{array}$ \\
\hline
\end{tabular}


FLAIR sequence

Stavanger TR/TE/TI/FA $6,000 \mathrm{~ms} / 100 \mathrm{~ms} / 2,000 \mathrm{~ms} / 90^{\circ}, \mathrm{ST}=4 \mathrm{~mm}$ with $5 \mathrm{~mm}$ spacing,

University $\quad \mathrm{NEX}=2$, Image Matrix $=256 \times 256$, FOV $23.0 \mathrm{~cm}, \mathrm{VS}=0.8984 \times 0.8984 \times 4 \mathrm{~mm}$.

Hospital

Haugesund TR/TE/TI/FA $6,000 \mathrm{~ms} / 110 \mathrm{~ms} / 2,000 \mathrm{~ms} / 90^{\circ}, \mathrm{ST}=4 \mathrm{~mm}$ with $5 \mathrm{~mm}$ spacing,

Hospital $\quad \mathrm{NEX}=2$, FOV $24.0 \mathrm{~cm}$, Image Matrix $=512 \times 512$, VS $=0.4688 \times 0.4688 \times 4 \mathrm{~mm}$.

Haraldsplass $\quad \mathrm{TR} / \mathrm{TE} / \mathrm{TI} / \mathrm{FA}=7,927 \mathrm{~ms} / 105 \mathrm{~ms} / 1,981 \mathrm{~ms} / 90^{\circ}, \mathrm{ST}=4 \mathrm{~mm}$ with $5 \mathrm{~mm}$ spacing,

deaconess $\quad \mathrm{NEX}=1$, Image Matrix $256 \times 256$, FOV $25.0 \mathrm{~cm}$, VS $=0.9766 \times 0.9766 \times 4 \mathrm{~mm}$.

hospital,

Bergen

Bergen TR/TE/TI/FA 8,400/103/2,500/150, ST = $4 \mathrm{~mm}$ with $4.4 \mathrm{~mm}$ spacing, NEX 2, Image Matrix $256 \times 204$, VS $=0.9766 \times 0.9766 \times 4 \mathrm{~mm}$.

Arendal $\quad$ TR/TE/TI/FA $6,000 / 100 / 1,900 / 90^{\circ}, \mathrm{ST}=4 \mathrm{~mm}$ with $5 \mathrm{~mm}$ spacing, NEX 2, Image Matrix $256 \times 256$, FOV $23.0 \mathrm{~cm}$ og VS $=0.8984 \times 0.8984 \times 4 \mathrm{~mm}$.

Scanner The human phantoms were scanned twice, $1 \mathrm{~h}$ apart, in all centers to analyze reliability scanner reliability between centers. Scanning was organized with two separate sessions, analysis $\quad 1 \mathrm{~h}$ apart, on the same day. From these scans, the total brain white matter was segmented from the T1 image and the volume calculated for the two MRI acquisitions at all four centers using FreeSurfer (http://surfer.nmr.mgh.harvard.edu/).

\section{References}

$\checkmark 1$ Young VG, Halliday GM, Kril JJ: Neuropathologic correlates of white matter hyperintensities. Neurology 2008;71:804-811.

$\checkmark 2$ de Leeuw FE, de Groot JC, Achten E, Oudkerk M, Ramos LM, Heijboer R, Hofman A, Jolles J, van Gijn J, Breteler MM: Prevalence of cerebral white matter lesions in elderly people: a population based magnetic resonance imaging study. The Rotterdam Scan Study. J Neurol Neurosurg Psychiatry 2001; 70:9-14.

-3 Yoshita M, Fletcher E, Harvey D, Ortega M, Martinez O, Mungas DM, Reed BR, DeCarli CS: Extent and distribution of white matter hyperintensities in normal aging, MCI, and AD. Neurology 2006; 67:2192-2198.

-4 Roman GC, Tatemichi TK, Erkinjuntti T, Cummings JL, Masdeu JC, Garcia JH, Amaducci L, Orgogozo JM, Brun A, Hofman A, et al: Vascular dementia: diagnostic criteria for research studies. Report of the NINDS-AIREN International Workshop. Neurology 1993;43:250-260.

-5 Baezner H, Blahak C, Poggesi A, Pantoni L, Inzitari D, Chabriat H, Erkinjuntti T, Fazekas F, Ferro JM, Langhorne P, O’Brien J, Scheltens P, Visser MC, Wahlund LO, Waldemar G, Wallin A, Hennerici MG: Association of gait and balance disorders with age-related white matter changes: the LADIS Study. Neurology 2008;70:935-942.

-6 Barber R, Scheltens P, Gholkar A, Ballard C, McKeith I, Ince P, Perry R, O’Brien J: White matter lesions on magnetic resonance imaging in dementia with Lewy bodies, Alzheimer's disease, vascular dementia, and normal aging. J Neurol Neurosurg Psychiatry 1999;67:66-72.

-7 Prins ND, van Dijk EJ, den Heijer T, Vermeer SE, Jolles J, Koudstaal PJ, Hofman A, Breteler MM: Cerebral small-vessel disease and decline in information processing speed, executive function and memory. Brain 2005;128:2034-2041.

-8 Aarsland D, Rongve A, Nore SP, Skogseth R, Skulstad S, Ehrt U, Hoprekstad D, Ballard C: Frequency and case identification of dementia with Lewy bodies using the revised consensus criteria. Dement Geriatr Cogn Disord 2008;26:445-452.

-9 Aarsland D, Ballard CG, Halliday G: Are Parkinson's disease with dementia and dementia with Lewy bodies the same entity? J Geriatr Psychiatry Neurol 2004;17:137-145. 
-10 Lippa CF, Duda JE, Grossman M, Hurtig HI, Aarsland D, Boeve BF, Brooks DJ, Dickson DW, Dubois B, Emre M, Fahn S, Farmer JM, Galasko D, Galvin JE, Goetz CG, Growdon JH, Gwinn-Hardy KA, Hardy J, Heutink P, Iwatsubo T, Kosaka K, Lee VM, Leverenz JB, Masliah E, McKeith IG, Nussbaum RL, Olanow CW, Ravina BM, Singleton AB, Tanner CM, Trojanowski JQ, Wszolek ZK: DLB and PDD boundary issues: diagnosis, treatment, molecular pathology, and biomarkers. Neurology 2007; 68:812-819.

- 11 McKeith IG, Dickson DW, Lowe J, Emre M, O’Brien JT, Feldman H, Cummings J, Duda JE, Lippa C, Perry EK, Aarsland D, Arai H, Ballard CG, Boeve B, Burn DJ, Costa D, Del Ser T, Dubois B, Galasko D, Gauthier S, Goetz CG, Gomez-Tortosa E, Halliday G, Hansen LA, Hardy J, Iwatsubo T, Kalaria RN, Kaufer D, Kenny RA, Korczyn A, Kosaka K, Lee VM, Lees A, Litvan I, Londos E, Lopez OL, Minoshima S, Mizuno Y, Molina JA, Mukaetova-Ladinska EB, Pasquier F, Perry RH, Schulz JB, Trojanowski JQ, Yamada M: Diagnosis and management of dementia with Lewy bodies: third report of the DLB consortium. Neurology 2005;65:1863-1872.

-12 Thanvi B, Lo N, Robinson T: Vascular parkinsonism - an important cause of parkinsonism in older people. Age Ageing 2005;34:114-119.

-13 Londos E, Passant U, Gustafson L, Brun A: Neuropathological correlates to clinically defined dementia with Lewy bodies. Int J Geriatr Psychiatry 2001;16:667-679.

-14 Ghebremedhin E, Rosenberger A, Rub U, Vuksic M, Berhe T, Bickeboller H, de Vos RA, Thal DR, Deller T: Inverse relationship between cerebrovascular lesions and severity of Lewy body pathology in patients with Lewy body diseases. J Neuropathol Exp Neurol 2010;69:442-448.

-15 Burton EJ, McKeith IG, Burn DJ, Firbank MJ, O’Brien JT: Progression of white matter hyperintensities in Alzheimer disease, dementia with Lewy bodies, and Parkinson disease dementia: a comparison with normal aging. Am J Geriatr Psychiatry 2006;14:842-849.

-16 Alves G, Muller B, Herlofson K, HogenEsch I, Telstad W, Aarsland D, Tysnes OB, Larsen JP: Incidence of Parkinson's disease in Norway: the Norwegian ParkWest study. J Neurol Neurosurg Psychiatry 2009;80:851-857.

$\checkmark 17$ Hafsteinsdottir SH, Eiriksdottir G, Sigurdsson S, Aspelund T, Harris TB, Launer LJ, Gudnason V: Brain tissue volumes by APOE genotype and leisure activity - the AGES-Reykjavik Study. Neurobiol Aging 2012;33:829.e821-829.e828.

- 18 Hachinski VC, Iliff LD, Zilhka E, Du Boulay GH, McAllister VL, Marshall J, Russell RW, Symon L: Cerebral blood flow in dementia. Arch Neurol 1975;32:632-637.

-19 Molsa PK, Paljarvi L, Rinne JO, Rinne UK, Sako E: Validity of clinical diagnosis in dementia: a prospective clinicopathological study. J Neurol Neurosurg Psychiatry 1985;48:1085-1090.

20 O’Bryant SE, Waring SC, Cullum CM, Hall J, Lacritz L, Massman PJ, Lupo PJ, Reisch JS, Doody R: Staging dementia using clinical dementia rating scale sum of boxes scores: a Texas Alzheimer's Research Consortium Study. Arch Neurol 2008;65:1091-1095.

-21 McKhann G, Drachman D, Folstein M, Katzman R, Price D, Stadlan EM: Clinical diagnosis of Alzheimer's disease: report of the NINCDS-ADRDA work group under the auspices of Department of Health and Human Services Task Force on Alzheimer's Disease. Neurology 1984;34:939-944.

-22 Fritze F, Ehrt U, Sonnesyn H, Kurz M, Hortobagyi T, Nore SP, Ballard C, Aarsland D: Depression in mild dementia: associations with diagnosis, APOE genotype and clinical features. Int J Geriatr Psychiatry 2011;26:1054-1061.

-23 Sonnesyn H, Oppedal K, Greve OJ, Fritze F, Auestad BH, Nore SP, Beyer MK, Aarsland D: White matter hyperintensities and the course of depressive symptoms in elderly people with mild dementia. Dement Geriatr Cogn Dis Extra 2012;2:97-111.

-24 Firbank MJ, Lloyd AJ, Ferrier N, O’Brien JT: A volumetric study of MRI signal hyperintensities in late-life depression. Am J Geriatr Psychiatry 2004;12:606-612.

-25 Firbank MJ, Minett T, O'Brien JT: Changes in DWI and MRS associated with white matter hyperintensities in elderly subjects. Neurology 2003;61:950-954.

-26 Hattori T, Orimo S, Aoki S, Ito K, Abe O, Amano A, Sato R, Sakai K, Mizusawa H: Cognitive status correlates with white matter alteration in Parkinson's disease. Hum Brain Mapp 2012;33:727-739.

-27 Fazekas F, Kleinert R, Offenbacher H, Schmidt R, Kleinert G, Payer F, Radner H, Lechner H: Pathologic correlates of incidental MRI white matter signal hyperintensities. Neurology 1993;43:1683-1689.

-28 Scheltens P, Barkhof F, Leys D, Pruvo JP, Nauta JJ, Vermersch P, Steinling M, Valk J: A semiquantative rating scale for the assessment of signal hyperintensities on magnetic resonance imaging. J Neurol Sci 1993;114:7-12. 
-29 Wahlund LO, Barkhof F, Fazekas F, Bronge L, Augustin M, Sjogren M, Wallin A, Ader H, Leys D, Pantoni L, Pasquier F, Erkinjuntti T, Scheltens P: A new rating scale for age-related white matter changes applicable to MRI and CT. Stroke 2001;32:1318-1322.

-30 van Straaten EC, Fazekas F, Rostrup E, Scheltens P, Schmidt R, Pantoni L, Inzitari D, Waldemar G, Erkinjuntti T, Mantyla R, Wahlund LO, Barkhof F: Impact of white matter hyperintensities scoring method on correlations with clinical data: the LADIS study. Stroke 2006;37:836-840.

- 31 Gouw AA, Van der Flier WM, van Straaten EC, Barkhof F, Ferro JM, Baezner H, Pantoni L, Inzitari D, Erkinjuntti T, Wahlund LO, Waldemar G, Schmidt R, Fazekas F, Scheltens P: Simple versus complex assessment of white matter hyperintensities in relation to physical performance and cognition: the LADIS study. J Neurol 2006;253:1189-1196.

-32 Tiehuis AM, Vincken KL, Mali WP, Kappelle LJ, Anbeek P, Algra A, Biessels GJ: Automated and visual scoring methods of cerebral white matter hyperintensities: relation with age and cognitive function. Cerebrovasc Dis 2008;25:59-66.

-33 Firbank MJ, O’Brien JT, Pakrasi S, Pantoni L, Simoni M, Erkinjuntti T, Wallin A, Wahlund LO, van Straaten I, Inzitari D: White matter hyperintensities and depression - preliminary results from the LADIS study. Int J Geriatr Psychiatry 2005;20:674-679.

-34 Resnick SM, Pham DL, Kraut MA, Zonderman AB, Davatzikos C: Longitudinal magnetic resonance imaging studies of older adults: a shrinking brain. J Neurosci 2003;23:3295-3301.

35 Zeng QS, Li CF, Liu ZQ, Lou L, Cui Y: [quantitative analysis of brain volume by in vivo magnetic resonance imaging in normal adults]. Zhongguo Yi Xue Ke Xue Yuan Xue Bao 2006;28:795-798.

-36 Ystad MA, Lundervold AJ, Wehling E, Espeseth T, Rootwelt H, Westlye LT, Andersson M, Adolfsdottir S, Geitung JT, Fjell AM, Reinvang I, Lundervold A: Hippocampal volumes are important predictors for memory function in elderly women. BMC Med Imaging 2009;9:17.

-37 Dyrby TB, Rostrup E, Baare WF, van Straaten EC, Barkhof F, Vrenken H, Ropele S, Schmidt R, Erkinjuntti T, Wahlund LO, Pantoni L, Inzitari D, Paulson OB, Hansen LK, Waldemar G: Segmentation of age-related white matter changes in a clinical multi-center study. Neuroimage 2008;41:335-345.

- 38 Jovicich J, Czanner S, Han X, Salat D, van der Kouwe A, Quinn B, Pacheco J, Albert M, Killiany R, Blacker D, Maguire P, Rosas D, Makris N, Gollub R, Dale A, Dickerson BC, Fischl B: MRI-derived measurements of human subcortical, ventricular and intracranial brain volumes: reliability effects of scan sessions, acquisition sequences, data analyses, scanner upgrade, scanner vendors and field strengths. Neuroimage 2009;46:177-192.

- 39 Kruggel F, Turner J, Muftuler LT: Impact of scanner hardware and imaging protocol on image quality and compartment volume precision in the ADNI cohort. Neuroimage 2010;49:2123-2133. 